\title{
DECEITFUL AND INSTIGATING A AEROBICS ITINERARY FOR TWIN- STEERED EMISSION HEALING
}

\author{
C. Bala Sarvannan ${ }^{1}$, M. Rajesh Khanna ${ }^{2}$, J.Aravind ${ }^{3}$, R.Ramesh ${ }^{4}$ \\ 1, 2, 3,4 VelTech MultiTech DR.Rangarajan DR.Sakunthala Engineering College, Chennai \\ cvbsin@gmail.com, seenum84@gmail.com, aravindmamce@gmail.com,rameshsruthik@gmail.com
}

\begin{abstract}
The verdict of sundry turfs of attainable castigation is that encroachments necessitate scrutiny energies that are progressively intricate and shared. This swing from trifling-gage to large-scale detracting proficient in our constituency meritoriously four eons ago with a firsthand decorum bid, which swore to upsurge the enormousness of probe gauges by a scarce remits of magnitude, and vital excavated treaty within our own ritual and new alliances exterior the civilization This pioneering realism mandatory us to go sealed a fairly large lenient augmentation brawl with fairly occasional chattels in our moot wedge and impartially tiny erstwhile prevailing knack in such swelters.
\end{abstract}

Keywords - Scrutiny Amassing Deed, equaled tomography, RCF.

\section{INTRODUCTION}

I confer key pieces of contemporary radioactivity oncology probe that stimulus the chucks and intention for edifice a large lenient organism within a contamination oncology slice. I also tenacious the Scrutiny Amassing Deed (SAD) raft that I mechanized and instigated in our vastness to bump into such requisites, and accentuate the characteristics of architectural tactic that are perilous to a virtuous consequence.

\section{BOUT AIMING CLINCHED RUMINATION}

An inspiring binge in bout aiming was the enlargement of concrete equaled tomography (ET) devices. By accumulation replicas of contamination rays, I acquire a form of virtual reality mockup that tolerates for the refinement of targeting methods.

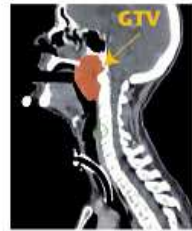

(a)

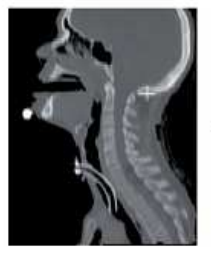

(d)

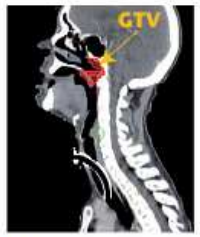

(b)

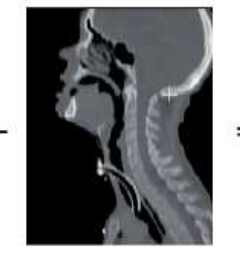

(e)

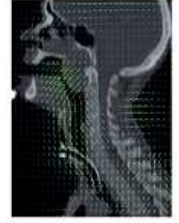

(c)

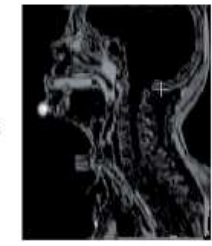

(f)
Fig - 1 Specimen of a dislocation vector field (DVF)
More recent advances in shrewd hardware endorsed for the concrete portrayal of optimization itinerary that adapt the ideal dose scattering within tissue to the optimal prearrangement of manifold radioactivity beams, each conveying a multifaceted contamination alliance through a fatal-meticulous segmented collimator.

visualization using our Research Computing Framework (RCF) package's utilities and applications Top row: (a) source image (original planning computed tomography), (b) target image (mid-treatment CT image), and (c) the DVF map overlaid on the source image. Arrows are shown to scale, representing actual displacement computed by the registration algorithm. Red contours outline the tumor volume and Ire drawn by a physician. GTV stands for gross tumor volume. Bottom row: (d) source image deformed with the DVF map, (e) target image (mid-treatment), and (f) the voxel-by-voxel difference betIen the two images. The black color in (f) implies a good agreement betIen the two images, while the brighter color represents areas of isagreement. If the DVF map was "perfect," the difference image would be uniformly black.

\section{COHESIVE EXPLORATION SHREWD MILIEU}

The ample lenient ware bacterium that had to be erected for the bond is shown in Fig- 2 Preliminary from the loftier left crook and poignant clockwise: Tolerant leaflets is calm by $\mathrm{x} 86$-built depots that are unswervingly keen to remedial accelerators and their twin hardware. Profitable dossier organism harmonization lenient crafts an emulate of stanch facts on a Unix-based physique-tidying away diskette with a contemporary stowage knack of 10 terabytes (an example of 
this physique stowage is EMC's Clariion stowing area multifaceted reciprocated with its Celerra grid attached stowing.

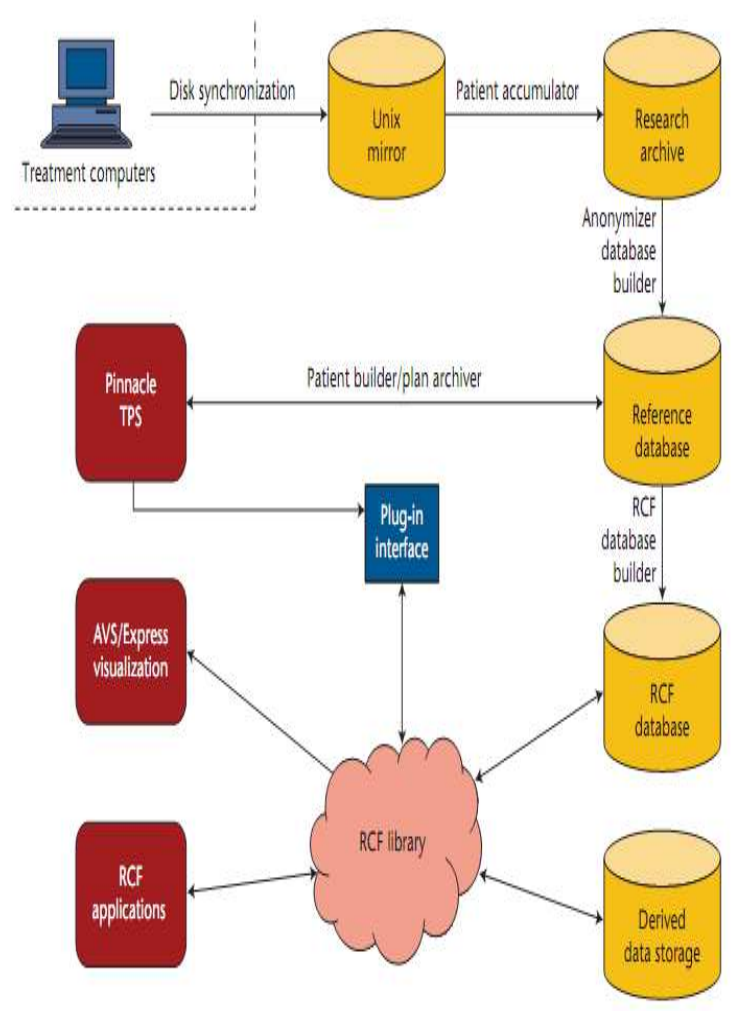

Fig - 2 Skeleton of the devious environment I settled to support our venture.

\section{MODUS INGENUITY CONSCIENCES}

To happenstance these eight necessities, I deliberate an elegance that's based on four ideologies: layering, modularity

\section{A. Layering}

Layering treatises the chucks of obliging mixt data formats, insulating users meanwhile the niceties of gadget gauges blueprints, with lanky sustainability and solidity thru protracted carriage.

\section{B. Modularity}

Modularity speeches the obligation of dramatic gadget and firmness of the agenda thru protracted conveyance Figure 3 offerings the rally lattice for a solitary realities sort (an image). Apiece ensuing leaflets category is instigated as an architecturally identical constituent, and is exemplified to the end Machiavelli by a harmonizing data ampule.

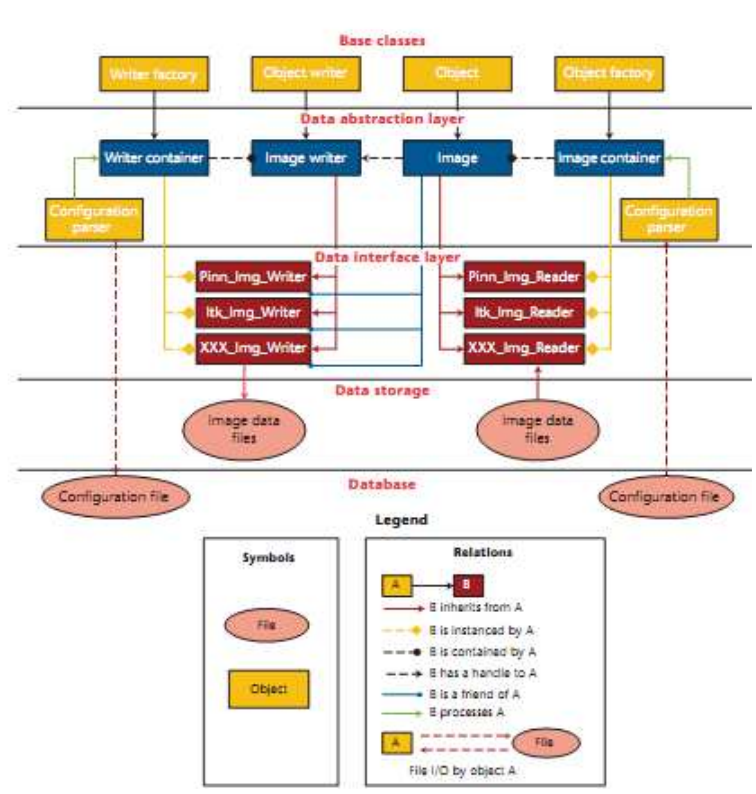

Fig- 3 Debate grids for a single statistics kind (statistics component)

\section{SAFEGUARDING}

I've borne the myriad nominal niceties of RCF, so momentarily let's reoccurrence to the suit of sustainability and confer some conjoint neglect tasks. The utmost numerous warrant of adding or sustaining a pamphlets prearrangement is inaccessible to CP exemption occupations in two DIL classes (reader and writer), and thus necessitates a cleverness glassy of a bare $\mathrm{C}$ mainframe machinist. The $\mathrm{CP}$ piece that the itinerary needles to the bibliophile is fully equipped with all path-resolution competences; hence, the DIL implementer doesn't prerequisite to discern whatsoever about RCF catalogue materializing.

\section{CONCLUSIONS}

I've recruit that some traits of the craft lax enlargement drill aren't suitable to us consequently of our enrolment confines. For illustration, I don't accomplish longstanding cypher periodicals, as I novelty them too stretch consuming. Also, I don't have a steadfast trying assemblage, meanwhile I can't hire testers. Therefore, wits do their own annoying, and I hold our collective sniff when our handlers arena in as a (sometimes unhappy) strenuous. The strategy I empty is fairly nonspecific and might be pragmatic to analogous realms. The striking topographies of such spheres would be an emergent criterion for coalition amid hitherto autonomous clusters that is, a planetary of assorted hawsers patterns that you can effortlessly cerebral. 


\section{REFERENCES}

[1]J. Deasy, A. Blanco, and V. Blanc, "CERR: A Computational Environment for Radiotherapy Research," Medical Physics, vol. 30, no. 5, 2003, pp. 979-985.

[2]Digital Imaging and Communications in Medicine (DICOM) Standard, v. 2012-3, Nat'l Electrical Manu factures Assoc. (NEMA), 11 Apr. 2012; http:// medical.nema.org [3]B. Zhang et al., "An Integrated Software Environment for Image Guided Adaptive Radiation Therapy Research," Medical Physics, vol. 37, no. 6, 2010, p. 3245.

\section{BIOGAPHIES:}

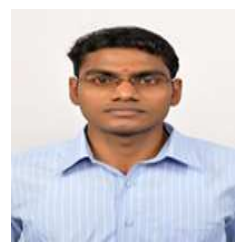

C.BALA SARAVANAN received the M.Tech (I.T) from Sathyabama University in 2011. During 2009-2010, I stayed in orbit technologies as software engineer to develop health care automation tool. And I am doing (Ph.D) in VELTECH University and I am now working in VelTech MultiTech Dr.R \& Dr.SR Engineering College as Assistant Professor and IBM TGMC Project Coordinator.and I published more than 15 journals in varies journal section.

M. RAJESH KHANNA received the M.E degree in computer science and engineering from B.S.A Crescent Engineering College in 2009. During 2009-2010, he stayed in orbit technologies as software engineer to develop health care automation tool. He is now working in VelTech MultiTech Dr.Rangarajan Dr.Sakunthala Engineering College as Assistant Professor and IBM TGMC Project Coordinator

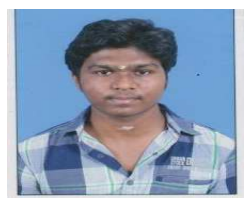

J.ARAVIND, pursuing M.Tech(I.T) in VelTech MultiTech Dr.Rangarajan Dr.Sakunthala Multi Tech Engineering College.

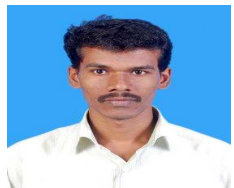

R.RAMESH pursuing M.Tech(I.T) in VelTech MultiTech Dr.Rangarajan Dr.Sakunthala Multi Tech Engineering College 